\title{
Gangguan Perilaku pada Anak Perempuan dengan Hiperplasia Adrenal Kongenital: Persepsi Orang Tua
}

\author{
Nida Hanifah, ${ }^{1}$ Annastasia Ediati, ${ }^{2}$ Mahayu Dewi Ariani, ${ }^{3}$ Sultana MH Faradz, ${ }^{3}$ Agustini Utari ${ }^{3,4}$ \\ ${ }^{1}$ Program Studi Kedokteran Fakultas Kedokteran, ${ }^{2}$ Fakultas Psikologi, ${ }^{3}$ Center for Biomedical Research (CEBIOR), ${ }^{4}$ Bagian Ilmu
} Kesehatan Anak Fakultas Kedokteran Universitas Diponegoro, Semarang

Latar belakang. Paparan androgen sejak prenatal diduga berdampak pada banyak aspek perkembangan anak perempuan dengan Hiperplasia Adrenal Kongenital (HAK). Namun, data mengenai gangguan emosi atau gangguan perilaku pada anak dengan HAK di Indonesia masih terbatas.

Tujuan. Mengetahui problem emosi/perilaku pada anak dengan HAK.

Metode. Penelitian ini menggunakan desain belah lintang. Subyek penelitian diambil dari 11 anak perempuan dengan HAK berumur 6-18 tahun. Kontrol $(n=11)$ diambil dari anak tanpa HAK dengan umur dan jenis kelamin yang sesuai dengan sampel. Data diambil dengan kuesioner CBCL/6-18 yang diisi oleh orang tua. Analisis data menggunakan Uji Mann-Whitney untuk melihat perbedaan skor antara anak dengan HAK dan tanpa HAK.

Hasil. Terdapat perbedaan perilaku yang signifikan antara anak dengan HAK dan kontrol $(\mathrm{p}<0,05)$ dalam hal problem sosial, problem perhatian, perilaku agresif, dan gangguan perilaku secara keseluruhan (skor total). Ada kecenderungan anak dengan HAK mengalami lebih banyak problem internalisasi daripada anak tanpa HAK, tetapi statistik kurang mendukung ( $\mathrm{p}=0,052)$. Namun demikian, nilai T-score pada anak dengan HAK masih dalam rentang normal $(\mathrm{T}<65)$.

Kesimpulan. Asesmen dan pendampingan psikologis bagi anak dengan HAK sangat diperlukan, terutama pada anak perempuan dengan HAK. Penanganan HAK secara dini dapat segera dilakukan untuk mencegah eskalasi problem psikologis pasca pubertas. Sari Pediatri 2020;22(2):65-70

Kata kunci: hiperplasia adrenal kongenital, CBCL/6-18, gangguan perilaku

\section{Behavior Disorders in Girls with Congenital Adrenal Hyperplasia: Parents Perceptions}

\author{
Nida Hanifah, ${ }^{1}$ Annastasia Ediati, ${ }^{2}$ Mahayu Dewi Ariani, ${ }^{3}$ Sultana MH Faradz, ${ }^{3}$ Agustini Utari ${ }^{3,4}$
}

Background. It has been known that prenatal androgen exposure impacts the affected child's development, particularly in girls with congenital adrenal hyperplasia (CAH). However, there are still contradictive opinions regarding behavioral disorders in children with $\mathrm{CAH}$ and limited data on behavioral disorders in children with $\mathrm{CAH}$ in Indonesia.

Objective. To evaluate the emotional/behavior disorders in children with CAH

Method. This study used a cross-sectional design. The population study was 11 girls with CAH aged 6-18 years. Controls ( $\mathrm{n}=11$ ) were taken from matched healthy children. Data was obtained from the parents by filling out the CBCL/6-18 questionnaire. The Mann-Whitney test was used to determine the score differences between CAH and non-CAH.

Results. There were significant differences $(\mathrm{p} \leq 0.05)$ between CAH children and non-CAH children on social problems, attention problems, aggressive behavior, and a total-score. There was a tendency for children with CAH to experience internalization problems than controls, but the statistics were less supportive $(\mathrm{p}=0.052)$. However, the T-score for children with CAH were still in the normal range $(\mathrm{T}<65)$.

Conclusion. Psychological assessment and support should be considered for patients, particularly for girls with CAH. Early CAH treatment is needed to prevent the escalation of psychological problems after puberty. Sari Pediatri 2020;22(2):65-70

Keywords: congenital adrenal hyperplasia, CBCL / 6-18, behavioral problem

Alamat korespondensi: Agustini Utari. Bagian Ilmu Kesehatan Anak Fakultas Kedokteran Universitas Diponegoro. Jl. Prof H.Sudharto, SH, Tembalang, Semarang-50275. Email: agustiniutari@gmail.com 
Nida Hanifah dkk: Gangguan perilaku anak perempuan dengan HAK: persepsi orang tua

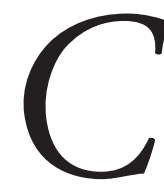

ongenital adrenal hyperplasia $(\mathrm{CAH})$ atau hiperplasia adrenal kongenital (HAK) merupakan suatu kelainan autosomal resesif yang mengganggu sintesis steroid. ${ }^{1}$ Kasus HAK terbanyak disebabkan oleh defisiensi 21-hidroksilase adalah kelainan pada korteks adrenal yang ditandai dengan defisiensi kortisol dan kadang defisiensi aldosteron. ${ }^{1,2}$ Kekurangan ini memberi sinyal ke hipotalamus dan hipofise untuk memproduksi lebih banyak corticotropin releasing hormone $(\mathrm{CRH})$ dan adrenocorticotropic hormone (ACTH) yang menyebabkan kelenjar adrenal menjadi hiperplastik. ${ }^{3}$ Akibat produksi androgen yang berlebihan, individu dengan HAK klasik menunjukkan maskulinisasi, salah satunya adalah adanya ambigus genitalia pada anak perempuan, dan perilaku yang lebih agresif. 4,5

Data skrining neonatal secara global yang melibatkan 6,5 juta bayi baru lahir menunjukkan insidensi 1 dari 15.000 bayi mengalami $\mathrm{HAK}^{2,6,7}$ sehingga penyakit ini juga termasuk dalam kelainan langka. Di Indonesia sendiri belum ada publikasi data nasional yang menunjukkan jumlah anak yang mengalami HAK, tetapi dari data registri UKK Endokrinologi Anak IDAI tercatat hampir 400 anak diketahui terdiagnosis dengan HAK. Meskipun perilaku yang lebih agresif pada anak dengan HAK telah dilaporkan berhubungan dengan peningkatan produksi androgen, ${ }^{4,5}$ penelitian lain menunjukkan tidak ada perbedaan perilaku yang signifikan pada anak perempuan dengan HAK yang terdeteksi sejak awal dan mendapat terapi yang adekuat. ${ }^{8}$ Berdasarkan pertimbangan bahwa masih ada perbedaan yang kontradiktif mengenai gangguan perilaku pada anak dengan HAK dan terbatasnya data tentang gangguan perilaku pada anak dengan HAK di Indonesia, maka peneliti ingin mengetahui gangguan perilaku pada anak dengan HAK menggunakan kuesioner CBCL/6-18.

Children behavior checklist (CBCL)/6-18 merupakan salah satu instrumen yang digunakan untuk menilai masalah perilaku dan kompetensi sosial pada anak umur 6-18 tahun. Kuesioner CBCL telah digunakan secara luas di seluruh dunia untuk mengevaluasi anak dengan penyakit kronis. CBCL/618 telah banyak diterjemahkan ke dalam beberapa bahasa termasuk bahasa Indonesia dan telah divalidasi untuk digunakan. ${ }^{9-12}$ Tujuan penelitian ini adalah untuk menilai gangguan emosi/perilaku pada anak perempuan dengan HAK.

\section{Metode}

Penelitian ini merupakan penelitian belah lintang yang dilakukan di Center for Biomedical Research (CEBIOR), Fakultas Kedokteran Universitas Diponegoro (FKUNDIP) - RS Nasional Diponegoro (RSND), Semarang, Jawa Tengah. Pengambilan data dilakukan pada April 2018 hingga Desember 2018. Kriteria inklusi kelompok sampel adalah anak perempuan berumur 6-18 tahun, terdiagnosis dengan HAK dan tanpa penyakit lainnya serta mendapat terapi hidrokortison dengan dosis standar. Kriteria eksklusi adalah ditemukannya riwayat penyakit sistemik lain yang dipandang memengaruhi terapi HAK dan terdapat komplikasi yang bukan disebabkan oleh terapi yang diberikan pada tata laksana HAK. Kelompok kontrol dipilih dari anak perempuan tanpa HAK yang disesuaikan berdasarkan umur dan karakteristik lingkungan yang menyerupai sampel kelompok anak dengan HAK.

Data problem perilaku diperoleh dari skor kuesioner CBCL/6-18 yang diisi oleh orang tua pasien. CBCL/6-18 menilai perilaku masa kanak-kanak pada tiga skala utama, yaitu problem keseluruhan, problem eksternalisasi, dan problem internalisasi serta menilai delapan subskala, yaitu cemas/tertekan, menarik diri, keluhan somatik, problem sosial, problem pikiran, problem atensi, perilaku nakal, dan perilaku agresif. Interpretasi hasil skor total (T-score) adalah sebagai berikut $<65=$ normal, $65-70=$ borderline, dan $>70=$ kemungkinan klinis gangguan perilaku.

Data tersebut kemudian dianalisis menggunakan program perangkat lunak SPSS versi 23. Data dianalisis menggunakan uji Mann-Whitney. Tingkat kemaknaan dalam penelitian ini dinyatakan bila $\mathrm{p}<0,05$.

Penelitian ini telah memperoleh kelaikan etik dari Komisi Etik Penelitian Kesehatan (KEPK) Fakultas Kedokteran Universitas Diponegoro (FK UNDIP) / RSUP Dr. Kariadi Semarang (Nomer : 545/EC/FKRSDK/VIII/2018). Informed consent didapatkan dari orang tua.

\section{Hasil}

Dari 62 anak dengan HAK yang tercatat di CEBIOR, terdapat 11 anak perempuan dengan HAK yang memenuhi kriteria inklusi. Kelompok kontrol berjumlah 11 anak dengan rentang umur dan 
karakteristik lingkungan yang menyerupai sampel kelompok anak dengan HAK. Karakteristik sampel dari penelitian ini tertera pada Tabel 1 .

Tabel 2 menunjukkan bahwa dari 11 sampel anak dengan HAK dan tanpa HAK didapatkan hasil perbedaan yang signifikan $(\mathrm{p}<0,05)$ pada subskala problem sosial, atensi, perilaku agresif, dan skor total skala. Sementara pada subskala kecemasan, menarik diri, keluhan somatik, problem pikiran, perilaku nakal, problem internalisasi, dan problem eksternalisasi tidak terdapat perbedaan yang signifikan $(p>0,05)$.

Gambar 1 menunjukkan adanya kecenderungan perbedaan skor subskala perilaku eksternalisasi pada anak dengan HAK dan anak tanpa HAK dimana sebaran data perilaku eksternalisasi cenderung lebih tinggi pada anak dengan HAK. Namun uji statistik kurang mendukung perbedaan data dua kelompok ini $(\mathrm{p}=0,052)$.

Tabel 1. Karakteristik subyek penelitian

\begin{tabular}{lccc}
\hline Variabel & Total & \multicolumn{2}{c}{ Kelompok } \\
\cline { 3 - 4 } & & Anak dengan HAK (n=11) & Anak tanpa HAK (n=11) \\
\hline Kelompok umur; $\mathrm{n}(\%)$ & $15(68,2)$ & $8(72,7)$ & $7(63,6)$ \\
Pre-pubertas (6-11 tahun) & $7(31,8)$ & $3(27,3)$ & $4(36,4)$ \\
Post-pubertas (12-18 tahun) & & & \\
Daerah tempat tinggal; $\mathrm{n}(\%)$ & $15(68,2)$ & $7(63,6)$ & $8(72,7)$ \\
Desa & $7(31,8)$ & $4(36,4)$ & $3(27,3)$ \\
Kota & &
\end{tabular}

Tabel 2. Perbedaan perilaku pada anak dengan HAK dan anak tanpa HAK

\begin{tabular}{llccc}
\hline Jenis problem emosi / problem perilaku & Kelompok anak $(\mathrm{n}=11)$ & Median & Skor min-maks & $\mathrm{p}^{*}$ \\
\hline Kecemasan & Dengan HAK & 4 & $0-9$ & 0,682 \\
Menarik diri & Tanpa HAK & 3 & $0-9$ & \\
& Dengan HAK & 2 & $0-7$ & 0,190 \\
Keluhan somatik & Tanpa HAK & 1 & $0-5$ & \\
& Dengan HAK & 4 & $0-8$ & 0,144 \\
Problem sosial & Tanpa HAK & 3 & $0-5$ & \\
& Dengan HAK & 4 & $1-6$ & 0,003 \\
Problem pikiran & Tanpa HAK & 2 & $0-4$ & \\
& Dengan HAK & 3 & $0-6$ & 0,611 \\
Problem atensi & Tanpa HAK & 1 & $0-7$ & \\
\multirow{3}{*}{ Perilaku nakal } & Dengan HAK & 6 & $1-11$ & 0,024 \\
Perilaku agresif & Tanpa HAK & 2 & $0-6$ & \\
& Dengan HAK & 2 & $0-17$ & 0,293 \\
Internalisasi & Tanpa HAK & 2 & $0-8$ & \\
Eksternalisasi & Dengan HAK & 8 & $0-17$ & 0,024 \\
Problem keseluruhan & Tanpa HAK & 3 & $0-10$ & \\
(Total) & Dengan HAK & 11 & $1-24$ & 0,175 \\
\hline
\end{tabular}

Keterangan: Analisis data menggunakan uji Mann-Whitney. Perbedaan dianggap bermakna jika $\mathrm{p}<0,05$ 


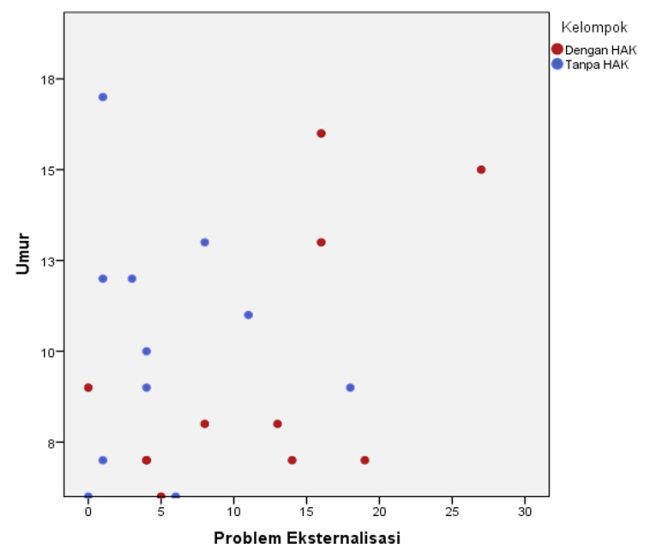

Gambar 1. Plot data skor subskala eksternalisasi pada anak dengan HAK dan anak tanpa HAK

\section{Pembahasan}

Penelitian ini membandingkan perilaku pada anakanak dengan HAK dan anak-anak tanpa HAK menggunakan instrumen kuesioner CBCL/6-18 yang merupakan salah satu alat yang digunakan untuk menilai masalah perilaku dan kompetensi sosial pada anak umur 6 sampai 18 tahun.

Hasil keseluruhan dari penelitian ini menunjukkan bahwa terdapat perbedaan perilaku yang signifikan antara anak dengan HAK dan tanpa HAK. Namun, skor rata-rata dari anak dengan HAK masih dalam rentang normal (T-score $<65)$. Hasil penelitian ini sesuai dengan penelitian yang dilakukan oleh Idris $\mathrm{dkk}^{9}$ pada tahun 2014 di Malaysia yang menggunakan instrumen yang sama menunjukkan hasil perbedaan T-score total yang signifikan, tetapi nilai $T$-score anak-anak dengan HAK dalam rentang normal.

Secara rinci, perilaku anak dengan HAK yang berbeda secara signifikan dibandingkan anak tanpa HAK mencakup perilaku dalam bergaul (problem sosial), pemusatan perhatian (problem atensi), perilaku agresif, dan problem perilaku secara umum (skala total). Penelitian Oner $\mathrm{dkk}^{13}$ juga menemukan bahwa remaja dengan HAK menunjukkan lebih banyak perilaku agresif dan problem perilaku secara umum daripada remaja tanpa HAK. Pada penelitian yang dilakukan oleh Ediati dkk, ${ }^{12}$ orang tua anak dengan disorder of sex development (DSD), termasuk HAK, melaporkan adanya problem sosial, problem atensi perhatian, perilaku agresif, dan problem eksternalisasi. Pada pasien DSD yang memiliki fitur tubuh atipikal yang menonjol seringkali mengalami problem emosi dan menarik diri dari interaksi sosial. Sementara pasien yang mampu menyembunyikan fitur tubuh atipikalnya tidak melaporkan problem tersebut. Hal ini berkaitan dengan stigmatisasi sosial. Mereka mengindikasikan bahwa stigmatisasi adalah stres, menimbulkan emosi negatif, menghambat partisipasi sosial dan karenanya memengaruhi kesejahteraan psikososial secara keseluruhan. ${ }^{14}$

Mathews $\mathrm{dkk}^{5}$ mengaitkan masalah agresi fisik dengan paparan androgen prenatal. Paparan androgen prenatal dapat mengubah beberapa karakteristik kepribadian wanita dengan HAK mengarah ke sifat pria. Penelitian Berenbaum dkk ${ }^{15}$ pada tahun 2000 menunjukkan hubungan yang tidak konsisten antara paparan androgen prenatal dengan sifat agresif, tetapi kuat kaitannya dengan pemilihan mainan tipe khas anak laki-laki. Sementara paparan androgen pascanatal tidak terkait dengan perilaku maskulinisasi karena kelebihan androgen pascanatal bervariasi antar individu dan berubah sepanjang waktu, tetapi hampir semua anak perempuan dengan HAK (kecuali mereka yang sakit ringan) lebih suka mainan anak laki-laki yang diukur pada dua waktu yang berbeda.

Penelitian Pasterski dkk ${ }^{16}$ pada tahun 2007 menunjukkan hasil peningkatan agresivitas dan aktivitas ditemukan hanya pada anak perempuan dengan HAK, sedangkan anak laki-laki dengan HAK tidak menunjukkan peningkatan yang signifikan.Penjelasan untuk kejadian ini adalah adanya mekanisme umpan balik yang mengurangi produksi androgen di testis sebagai respon terhadap peningkatan produksi androgen di testis.

Penjelasan ini konsisten dengan kadar androgen pada anak laki-laki dengan HAK masih dalam kadar normal. Namun, hal ini bertentangan dengan beberapa penelitian yang menunjukkan hasil berupa peningkatan perilaku maskulin pada laki-laki dengan HAK. Terdapat juga penelitian yang melaporkan adanya peningkatan agresivitas pada anak laki-laki dan perempuan yang terpapar androgenik progestin karena penggunaan hormon tersebut selama kehamilan oleh ibu dari sampel yang bersangkutan. ${ }^{16}$ Pada penelitian ini skor CBCL/6-18 pada anak HAK masih dalam kategori normal. Hal ini masih dimungkinkan karena beberapa yang memengaruhi, seperti terapi kepatuhan (compliance)yang bisa memengaruhi kadar testosteron, tetapi hal-hal tersebut tidak diamati dalam penelitian ini. 
Adanya problem psikopatologi pada anak dan remaja HAK dalam penelitian ini perlu mendapat perhatian lebih mendalam. Secara khusus perlu asesmen psikologis mendalam pada anak dan remaja dengan HAK sehingga dapat segera mendapat intervensi psikologis untuk membantu anak dan remaja dengan HAK agar dapat bergaul dengan lebih baik, memusatkan perhatian dengan lebih baik, dan mengelola perilaku agresif pada anak dan remaja pada HAK. Asesmen dan intervensi psikologis dalam kasus HAK perlu dilakukan dengan mempertimbangkan kasus per kasus.

Pada penelitian ini tidak ditemukan adanya perbedaan bermakna pada kecemasan, problem pikiran, menarik diri dari pergaulan, keluhan somatik, perilaku nakal, problem internalisasi, dan problem eksternalisasi antara anak dengan HAK dan anak tanpa HAK. Hal ini serupa dengan penelitian Maryniak $\mathrm{dkk}^{17}$ pada tahun 2014 yang menemukan tidak adanya perbedaan signifikan pada profil psikopatologi yang diukur menggunakan CBCL pada anak dan remaja dengan HAK yang menerima terapi dexametason dengan anak dan remaja yang tidak menerima terapi dexametason saat prenatal. Kelemahan penelitian ini adalah jumlah pasien HAK yang telah mencapai usia remaja sangat terbatas dan tidak membandingkan data testosteron anak dengan HAK dan kontrol.

\section{Kesimpulan}

Skor CBCL/6-18 anak dengan HAK lebih tinggi dibanding anak tanpa HAK, tetapi masih dalam rentang normal. Meskipun demikian, terdapat perbedaan yang bermakna pada anak dengan HAK dan anak tanpa HAK umur 6 sampai 18 tahun dimana anak dengan HAK memiliki lebih banyak problem emosi dan problem perilaku, terutama problem dalam bergaul, problem atensi, dan perilaku agresi yang diukur menggunakan CBCL/6-18. Anak umur 6 sampai 18 tahun dengan HAK tidak berbeda dari anak tanpa HAK dalam hal kecemasan, menarik diri, keluhan somatik, problem pikiran, perilaku nakal, problem internalisasi, dan problem eksternalisasi. Asesmen dan pendampingan psikologis bagi anak dengan HAK sangat diperlukan, terutama pada anak perempuan dengan HAK, agar penanganan dini dapat segera dilakukan untuk mencegah eskalasi problem psikologis pasca pubertas.

\section{Ucapan Terimakasih}

Penelitian ini didukung oleh dana hibah penelitian FK UNDIP 2018 (604/UN7.5.4/HK/PP/2018). Terimakasih untuk keluarga dengan HAK atas partisipasinya.

\section{Daftar pustaka}

1. Speiser PW, Arlt W, Auchus RJ, Baskin LS, Conway GS, Merke DP, dkk. Congenital adrenal hyperplasia due to steroid 21-hydroxylase deficiency: an Endocrine Society Clinical Practise Guidelines. J Clin Endocrinol 2018;103:4043-88.

2. Merke DP, Bornstein SR. Congenital adrenal hyperplasia. Lancet 2005;365:2125-36.

3. White PC, Speiser PW. Congenital adrenal hyperplasia due to 21-Hydroxylase deficiency. Endocr Rev 2000;21:245-91.

4. Meyer-Bahlburg HF, Dolezal C, Baker SW, New MI. Sexual orientation in women with classical or non-classical congenital adrenal hyperplasia as a function of degree of prenatal androgen excess. Arch Sex Behav 2008;37:85-99.

5. Mathews GA, Fane BA, Conway GS, Brook CG, Hines M. Personality and congenital adrenal hyperplasia: possible effects of prenatal androgen exposure. Horm Behav 2009; 55:285-91.

6. Witchel SF. Adrenal Disorders: genetics and pathophysiology of congenital adrenal hyperplasia. Dalam: Levine AC, penyunting. Adrenal Disorders. Pittsburgh (USA): Springer International Publishing; 2018.h.109-27.

7. Bara CH, Silva IN, Pezzuti IL, Januario JN. Neonatal Screening for congenital adrenal hyperplasia. Rev Assoc Med Bras 2012;58:459-64.

8. Berenbaum SA, Korman Bryk K, Duck SC, Resnick SM. Psychological adjustment in children and adults with congenital adrenal hyperplasia. J Pediatr 2004;144:741-6.

9. Idris AN, Chandran V, Syed Zakaria SZ, Rasat R. Behavioural outcome in children with congenital adrenal hyperplasia: experience of a single centre. Int J Endocrinol 2014;2014:483718.

10. Pandolfi V, Magyar CI, Dill CA. An initial psychometric evaluation of the CBCL 6-18 in a sample of youth with autism spectrum disorders. Res Autism Spectr Disord 2012;6:96-108.

11. Albores-Gallo L, Lara-Munoz C, Esperon-Vargas C, Cardenas Zetina JA, Perez Soriano AM, Villanueva Colin G. Validity and reliability of the CBCL/618 includes DSM scales. Actas Esp Psiquiatr 2007;35:393-9.

12. Ediati A, Faradz SM, Juniarto AZ, van der Ende J, Drop SL, Dessens AB. Emotional and behavioral problems in 
Nida Hanifah dkk: Gangguan perilaku anak perempuan dengan HAK: persepsi orang tua

late-identified Indonesian patients with disorders of sex development. J Psychosom Res 2015;79:76-84.

13. Oner O, Aycan Z, Tiryaki T, Soy D, Cetinkaya E, Kibar E. Variables related to behavioral and emotional problems and gender typed behaviors in female patientss with congenital adrenal hyperplasia. J Pediatr Endocrinol Metab 2009;22:143-151.

14. Ediati A, Juniarto AZ, Birnie E, Okkerse J, Wisniewski A, Drop $S$, dkk. Social stigmatisation in late identified patients with disorders of sex development in Indonesia. BMJ Paediatr Open 2017;1:1-9.

15. Berenbaum. SA, Duck. SC, Bryk. K. Behavioral effects of prenatal versus postnatal androgen excess in children with 21-hydroxylase deficient congenital adrenal hyperplasia. J Clin Endocrinol Metab 2000;85:727-33.

16. Pasterski V, Hindmarsh P, Geffner M, Brook C, Brain C, Hines $\mathrm{M}$. Increased aggression and activity level in 3- to 11-year-old girls with congenital adrenal hyperplasia Horm Behav 2007; 52:368-74

17. Maryniak A, Ginalska-Malinowska M, Bielaswska A, Ondruch A. Cognitie and social function in girls with congenital adrenal hyperplasia - Influence of prenatally administered dexamethasone. Child Neuropsychol 2014;20:60-70. 